\title{
The ChOpstick Auction: A STUdy OF THE ExPosure PROBlem In Multi-Unit AuCtions
}

\author{
FLORIAN ENGLMAIER \\ PABLO GUILLÉN \\ LORETO LLORENTE \\ SANDER ONDERSTAL \\ RUPERT SAUSGRUBER
}

CESIFO WORKING PAPER NO. 1782

CATEGORY 9: INDUSTRIAL ORGANISATION

August 2006

An electronic version of the paper may be downloaded

- from the SSRN website:

www.SSRN.com

- from the RePEc website:

Www.RePEc.org

- from the CESifo website:

www.CESifo-group.de 


\title{
THE CHOPSTICK AUCTION: A STUDY OF THE EXPOSURE PROBlem In MUlti-Unit AUCTIONS
}

\begin{abstract}
Multi-unit auctions are sometimes plagued by the so-called exposure problem. In this paper, we analyze a simple game called the 'chopstick auction' in which bidders are confronted with the exposure problem. We do so both in theory and in a laboratory experiment. In theory, the chopstick auction has an efficient equilibrium and is revenue equivalent with the second-price sealed-bid auction in which the exposure problem is not present. In the experiment, however, we find that the chopstick auction is less efficient than the second-price sealed-bid auction and that it yields more [the same] revenue if bidders are inexperienced [experienced].
\end{abstract}

JEL Code: C9, D44.

Keywords: chopstick auction, exposure problem, laboratory experiment, second-price sealedbid auction.

\author{
Florian Englmaier \\ Harvard Business School \\ Baker Library $444 A$ \\ USA - Boston, MA 02163 \\ fenglmaier@hbs.edu \\ Loreto Llorente \\ Public University of Navarra \\ Department of Economics \\ Spain - Pamplona \\ loreto.llorente@unavarra.es
}

\author{
Pablo Guillén \\ Harvard Business School \\ Baker Library $B 90$ \\ USA - Boston, MA 02163 \\ pguillen@hbs.edu \\ Sander Onderstal \\ University of Amsterdam \\ Amsterdam School of Economics \\ Roetersstraat 11 \\ 1018 WB Amsterdam \\ The Netherlands \\ onderstal@uva.nl
}

\author{
Rupert Sausgruber \\ University of Innsbruck \\ Department of Public Economics \\ Universitätsstr. 15 \\ Austria-6020 Innsbruck \\ rupert.sausgruber@uibk.ac.at
}

July 14, 2006 


\section{Introduction}

Multi-unit auctions are sometimes plagued by what is called the "exposure problem". We speak of an exposure problem when bidders aim at winning several units but are exposed to the risk of buying too few as competition on some of these units turns out to be tougher than expected. ${ }^{1}$ Several economists have argued that the exposure problem in auction should be prevented as it leads to an inefficient outcome of the auction and to low revenue. In this paper, we will investigate whether these claims are true, using a laboratory experiment.

Economic theory sketches a mixed picture about both claims. Theoretical papers by Robert Rosenthal and coauthors include situations in which the exposure problem is present. Szentes and Rosenthal (2003ab) find efficient equilibria in multi-unit auctions of homogeneous objects. However, Krishna and Rosenthal (1996) and Rosenthal and Wang (1996) construct inefficient equilibria in the case of heterogeneous objects. In these papers, the authors analyze multi-unit auctions with two types of bidders, namely "local" bidders who are interested in only one object, and "global" bidders who try to acquire several. The global bidders, in competition with the local ones, face the exposure problem when attempting to realize synergies between the objects. In line with this, Bykowsky et al. (2000) give an illustrative example in which the equilibrium outcome is such that either the allocation is inefficient or at least one of the bidders ends up paying more for the purchased items than they are worth to her.

Other theorists have investigated the relationship between efficiency and revenue. For auctions of perfectly divisible objects, Ausubel and Cramton (1999) show that efficiency of the auction outcome is necessary for revenue maximization when the auction is followed by a perfect resale market and when the seller cannot commit to not selling some units. However, usually there is a trade-off between efficiency and revenue. In Myerson's (1981) model, the seller maximizes his expected revenue by imposing a reserve price and hence

\footnotetext{
${ }^{1}$ See also Bykowsky et al. (2000), and Milgrom (2000).
} 
excluding bidders with low values from winning the object so that the outcome is not necessarily efficient. Milgrom (2000) constructs an example in which there is a trade-off between efficiency and revenue in the case of multi-unit auctions: the seller realizes a less efficient outcome when using larger packages but gets a higher revenue.

In practice, it is also not clear whether the exposure problem is a major issue. At least Klemperer (2002) does not include the warning "avoid the exposure problem" in his list of issues that are of practical importance in the design of (multi-unit) auctions. However, Van Damme (1999) claims that the exposure problem led to low bids and an inefficient outcome in the Dutch DCS-1800 auction. In February 1998, the Dutch government auctioned licenses for second generation mobile telecommunication using an auction with almost the same rules as the FCC auctions in the US. ${ }^{2}$ A difference between the Dutch DCS-1800 auction and the American auctions was that in the American auctions, the exposure problem was not seriously present as bidders were allowed to withdraw their bids. Van Damme argues that the FCC auction format would have lead to a higher revenue and a more efficient outcome.

Does the exposure problem indeed lead to inefficient outcomes and low revenues? In order to answer this question, we designed a laboratory experiment in which we confronted subjects with a simple auction game called "the chopstick auction" (CSA). ${ }^{3}$ In this auction, a seller simultaneously sells three chopsticks. There are 2 bidders in the auction, who independently submit a bid, which is the price for one chopstick. Call the second highest bid $p$. The outcome of CSA is such that the highest bidder gets two chopsticks for a price of $2 p$ and the second highest bidder gets one chopstick for $p$. We compared CSA with the second-price sealed-bid auction (SPSB) in which two chopsticks are sold as one bundle. The only difference with the "usual" second-price sealed-bid auction is that the winning bidder has to pay the second highest bid twice, once for each chopstick.

\footnotetext{
${ }^{2}$ See McMillan (1994), Cramton (1995, 1998), McAfee and McMillan (1996), and Milgrom (2000) for descriptions and discussions of these auctions.

${ }^{3}$ The credit for the name of this auction game goes to Mary Lucking-Reiley. Thanks to Balasz Szentes and Robert Rosenthal for pointing this out to us.
} 
We examine bidding behavior in CSA and in SPSB in the following setting. Bidder $i$ 's $(i=1,2)$ marginal values are zero on the first chopstick, $v_{i}$ on the second, and zero on the third. The signals $v_{i}$ are independently drawn from the same distribution. Because the second highest bidder wins a worthless chopstick for a positive price, bidders face the exposure problem in CSA.

CSA is never used in practice, but in our context, it is a good proxy for the uniform price auction and the simultaneous ascending auction. Some governments sell treasury bills using the uniform price auction, ${ }^{4}$ and the FCC auctions in the US and some of the UMTS auctions in Europe were of the simultaneous ascending auction type. ${ }^{5}$ CSA has the advantage over the other two auction formats that it is easier to implement in the lab because of its simplicity. To see why CSA is a good proxy for the uniform price auction and the simultaneous ascending auction, first, imagine that the three chopsticks are sold in a uniform price auction in which the highest three bids win, and the fourth bid determines the price. For both bidders, it is a weakly dominant strategy to bid the same amount on two chopsticks. Bidding positive amounts on only one chopstick or all three chopsticks is obviously not optimal. Moreover, any strategy that prescribes different bids is weakly dominated by bidding the lowest of the two amounts on two chopsticks. The outcome of the uniform price auction in which bidders bid $b$ on two objects is then the same as CSA in which a bid equal to $b$ is submitted.

Next, suppose that the three chopsticks are sold in the simultaneous ascending auction with an activity rule that forces bidders to be active on at most the same number of objects as in the previous round. In that case, it is an equilibrium to bid "straightforwardly", ${ }^{6}$ i.e. when submitting a bid, to bid the minimum price and to make sure to be active on exactly two objects, and to abstain from bidding when a specific price is reached. It does not make sense to submit a bid on only one license while not being active on

\footnotetext{
${ }^{4}$ See e.g. Binmore and Swierzbinski (2000).

${ }^{5}$ See, e.g., McMillan (1994) and Van Damme (2002).

${ }^{6}$ Börgers and Dustman (2005).
} 
another. Neither is it worth bidding on three objects as a third object is of no additional value. Finally, submitting different bids on different objects against a bidder who is bidding straightforwardly is not profitable. It is readily verified that a bidder is strictly better off by bidding the lowest of the two bids on both objects. If both bidders bid straightforwardly up to an amount $b$, the same outcome results (in terms of prices and allocation) as they would bid $b$ in CSA (abstracting from small deviations caused by a strictly positive minimum bid increment).

Another auction that is closely related to CSA (but rarely used in practice) is the all-pay auction. Suppose one object is sold. In the auction, bidders independently submit a sealed bid. The highest bidder wins the object but all bidders must pay their bid, even those who do not win the object. Note that bidders face the exposure problem here: the losing bidders fail to win the object but still has to pay a positive price. In laboratory experiments, Davis and Reilly (1998), Potters et al. (1998), and Noussair and Silver (2006) observe that subjects bid more in the all-pay auction than what would be expected in equilibrium with risk neutral bidders. This observations suggests that the exposure problem may be non-existent, at least not in terms of revenue. Barut et al. (2002), in an experiment that is closely related to ours, extend this result to all-pay auctions with multiple objects. The main difference with their design and ours is twofold. First, in our design, the losing bidder only pays half of her bid. Second, in CSA, the winner pays the second highest bid instead of her own.

In section 2, we study the theoretical properties of CSA and SPSB. ${ }^{7}$ We find that CSA has an efficient Bayesian Nash equilibrium. From standard auction theory we learn that SPSB has an efficient equilibrium in weakly dominant strategies in which each bidder submits a bid equal to half her value for each chopstick. The revenue equivalence theorem (Myerson, 1981) then implies that CSA is revenue equivalent with SPSB. In other words, in this theoretical setting, auctions in which the exposure problem is present perform as

\footnotetext{
${ }^{7}$ See Onderstal (2002) for a more detailed theoretical investigation of the chopstick auction.
} 
well as auctions in which it is not. That makes this setting a useful benchmark to test the two claims we started with.

In section 3, we describe the experimental design and discuss the results of the experiment. We used an "ABA-BAB" design, i.e., half of the subjects played CSA in the first 30 rounds, followed by SPSB, and CSA again, while it was the other way around for the other half. This design allows us to explore whether CSA and SPSB produce different outcomes and furthermore, whether such differences are robust with respect to learning.

We obtain the following results. First, in the first two phases of the experiment, revenue tends to be higher when bidders are confronted with the exposure problem than if they are not. This is in contrast to the third phase, in which CSA and SPSB do not differ statistically in terms of generated revenue. Our second finding is that SPSB is significantly more efficient than CSA in all phases. Our third observation may seem somewhat surprising: in SPSB, the average revenue was about $20 \%$ above revenue that would be generated if all bidders bid half their value (the unique weakly dominant strategy). This finding is robust across phases and across rounds and it is in contrast to what is found in experiments by Kagel et al. (1987), Kagel and Levin (1993), and Harstad (2000) on the "standard" second-price sealed-bid auction. In these experiments, the average revenue was only about $10 \%$ above the dominant strategy. ${ }^{8}$ A possible explanation of this result is that we have complicated the game somewhat: when winning, a bidder has to pay twice the second highest bid, once for each chopstick. This is different than what happens in the usual second-price sealed-bid auction, in which the winner pays the second highest bid only once. This framing effect shows that even a slight complication of the environment may make it harder for people to act rationally.

We conclude that our experiment gives a convincing reason why the advice "avoid the exposure problem" should be added to Klemperer's list of practical issues in the design of auctions. With experienced bidders, CSA yields the same revenue as SPSB but performs

\footnotetext{
${ }^{8}$ See Kagel (1995) for an overview of laboratory experiments on the second-price sealed-bid auction.
} 
worse in terms of efficiency.

\section{Theory}

Consider a situation with 2 bidders, labelled 1 and 2 , who wish to eat Chinese food. However, none of the bidders has anything to eat with. Suppose that a seller sells 3 chopsticks in the chopstick auction (CSA) which has the following rules. The price starts at zero and is continuously raised. Bidders have the opportunity to leave the auction at any price they desire. The auction ends when one bidder quits. She wins one chopstick and pays the price at which she leaves. The remaining bidder wins two chopsticks and pays two times the price at which the second highest bidder has quit. If there is a tie, the winner of the auction is determined by tossing a fair coin.

The value $V_{i}(s)$ bidder $i$ attaches to owning $s$ chopsticks is given by

$$
V_{i}(s)= \begin{cases}v_{i} & s=2,3 \\ 0 & s=0,1\end{cases}
$$

where $v_{i}$ is a private signal for bidder $i$. In words, a bidder attaches a value of $v_{i}$ to winning two chopsticks and no value to winning only one chopstick or to winning a third one. We assume that the $v_{i}$ 's are drawn independently from the same smooth distribution function $F$ with density function $f$. We assume that $f(w)>0$ for all $w \in[0,1]$.

Each bidder is risk neutral. In other words, if the price realized in CSA is equal to $p$, the utility for bidder $i$ having drawn a value equal to $v_{i}$ is given by

$$
u_{i}\left(v_{i}, s, p\right)=\left\{\begin{array}{ll}
v_{i}-2 p & s=2 \\
-p & s=1
\end{array} .\right.
$$

Observe that CSA is strategically equivalent to the following sealed-bid auction. The highest bidder, let's say $i$, wins an object with value $v_{i}$ and pays twice the bid of the other 
bidder. The other bidder receives nothing, but pays his bid once. We use this sealed-bid version in our laboratory experiment.

Proposition 1 gives equilibrium bidding in CSA. We can use Baye et al.'s (1998) analysis to construct the equilibrium bid function because CSA is a special case of their general linear model of contests. Baye et al. derive a differential equation from which the equilibrium bid function is uniquely determined.

Proposition 1 Let $B(v)$, the bid of a bidder with signal $v$, be given by

$$
B(v)=v-\int_{0}^{v} \frac{1-F(v)}{1-F(x)} d x
$$

Then $B$ is the unique symmetric Bayesian Nash equilibrium of CSA. The outcome of the auction is efficient. The bidder with the lowest possible value obtains zero utility.

Proof. See the appendix.

Let us compare the outcomes of CSA with the second-price sealed-bid auction in which two chopsticks are sold as one bundle (SPSB). Proposition 2 gives the equilibrium properties of SPSB.

Proposition 2 Let $b(v)$, the bid of a bidder with signal $v$, be given by

$$
b(v)=\frac{v}{2} .
$$

Then $b$ is the unique symmetric Bayesian Nash equilibrium in weakly dominant strategies of SPSB. The outcome of the auction is efficient. The bidder with the lowest possible value obtains zero utility.

Proof. Standard. 
Propositions 1 and 2 show that both auctions are efficient. In other words, a seller who is concerned about efficiency is indifferent between the two auction types.

Moreover, both auctions turn out to be revenue equivalent, and generate the same expected utility for the bidders. This is a direct consequence of the revenue equivalence theorem (Myerson, 1981), using the following two observations. First, both CSA and SPSB are auctions of a single object, namely a set of two chopsticks. Second, according to Propositions 1 and 2, both auctions are efficient and the utility of the bidder with the lowest possible value is equal to zero. The interpretation of this revenue equivalence result is that a risk neutral seller interested in revenue is indifferent between using CSA and SPSB to sell the chopsticks. Proposition 3 summarizes this finding.

Proposition 3 Suppose that bidders play CSA and SPSB according to the strategies given in Propositions 1 and 2 respectively. Then the auctions are revenue equivalent and the bidders expect the same utility in both auctions.

Proof. Standard.

\section{Laboratory experiment}

We present the results of our laboratory experiment in four parts. In the first part, we describe the experimental design. Part two presents total revenue generated by the auctions. In the third part, we focus on efficiency. In the final part, we analyze bidding behavior. 


\subsection{Experimental design}

In a computerized laboratory experiment, we studied CSA and SPSB in a setting that is closely related to the theoretical setting. ${ }^{9}$ The main differences are the following. First of all, the subjects in the lab were confronted with the sealed-bid version of CSA. Subjects did not see the price rise until one of them indicated to leave the auction. Instead, subjects were asked at which price they would desire to quit. However, the two games are strategically equivalent, so that we do not expect any differences in the outcomes. ${ }^{10}$ Secondly, we approximated the continuous signal and bidding spaces with fine grids. Thirdly, values were drawn according to a uniform distribution on a grid between 0 and 100 with 1 as the smallest step. Our theoretical results have been based on the assumption that bidders draw their signals from the interval $[0,100]$. Finally, subjects could choose prices from a finite grid between 0 and 999, with 1 as the smallest step. The theory has been based on the assumption that bidders can choose their bids from a continuous action space. However, both grids are sufficiently fine to approximate the continuous signal and action space.

The experiments were conducted at Harvard Business School in December 2005 and January 2006. We had 96 subjects participating in four sessions. We used an ABABAB design, i.e., in two sessions, 48 subjects played CSA in the first phase, SPSB in the second, and again CSA in the third, and 48 subjects played the other way around in the other two sessions. In all sessions, the subjects were separated in groups of four. Each phase consisted of three practice periods and 30 paid trading periods. Before the start of each period, the subjects were randomly re-matched to another player in their group of four, resulting in 12 independent observations per treatment. In each period, all subjects drew a new value for two chopsticks. At the beginning of each session, subjects read the

\footnotetext{
${ }^{9}$ The experiment has been programmed and conducted with the software Z-tree (Fischbacher, 1999).

${ }^{10}$ Still, we should be somewhat cautious, as "framing effects" may occur. For instance, in experiments by Coppinger et al. (1980) and Cox et al. (1982), the first-price sealed-bid auction turned out to generate higher prices than the Dutch auction, despite the fact that both games are strategically equivalent.
} 
instructions (see the appendix). Questions were answered privately.

Subjects were paid a lump sum transfer of $\$ 10$ for showing up and an additional reward equivalent to their earnings during the auctions. ${ }^{11}$ They earned ECU (Experimental Currency Units) which were calculated as the difference between the value of the chopsticks they won minus the price they paid. In order to accommodate losses, subjects received the equivalent of $\$ 3$ in ECU at the beginning of each phase. ${ }^{12}$ Points were exchanged into cash according to the exchange rate

$$
100 \mathrm{ECU}=\$ 1 .
$$

In CSA, the winner of just one chopstick gets a negative score equal to the amount he paid for it. The maximum score in a period is 100 points, i.e., the maximum value (100) minus the minimum payment (0). Subjects earned $\$ 26$ on average in approximately 2 hours (including $\$ 10$ for showing up on time and an additional payment of $\$ 3$ at the start of each phase).

\subsection{Results: revenue}

What is the average revenue in the auctions? In CSA, revenue equals three times the price: the winner of two chopsticks pays this price twice, the winner of one chopstick once. In SPSB, revenue is equal to twice the price. See figure 1 for the average revenue in each phase.

\section{[Insert Figure 1 about Here]}

\footnotetext{
${ }^{11}$ Paying every period as we did induces behavior towards risk neutrality. Paying according to one randomly selected period, instead, may increase subjects' willingness to take risks (Davis and Holt, 1993).

${ }^{12}$ If subjects managed to lose all their running balance, a screen would pop up informing that the upfront money was to be used to cover further losses. Subjects did not object to that. Only one subject managed to lose even her show-up fee. In this case we injected some money in her account $(\$ 5)$. She managed to earn $\$ 7$ after bankrupting. Excluding her group from the data analysis does not qualitative change our findings.
} 
Result 1 In the CSA treatments that took place in phases 1 and 2 [3], revenue was higher than [the same as] predicted by the theory. ${ }^{13}$

Inexperienced subjects, i.e., subjects that did not play CSA in earlier phases, turned out to pay much more than predicted by the theory. Given the realized values in the experiment, the average revenue would have been about 33 points per period if bidders had bid according to the bid function in Proposition 1. In reality, the average revenue was $72.6[50.2]$ points in the first [second] phase.

Result 2 In all phases, SPSB yields more revenue than predicted by the theory. ${ }^{14}$

For SPSB, the theory predicts that revenue would have been about 33 points on average per period. In all three phases of the experiment, average revenue was equal to about $20 \%$ more than the theoretical prediction. A possible explanation of this result is that we have complicated the game somewhat: when winning, a bidder has to pay twice the second highest bid, once for each chopstick. This is different than what happens in the "usual" second-price sealed-bid auction, in which the winner pays the second highest bid only once. Overbidding in SPSB may be driven by this framing. This result turns out to be robust in the sense that overbidding is still present in the third phase.

Result 3 In the treatments that took place in phases 1 and 2, CSA yields more revenue than SPSB. The revenues are not statistically different in phase $3 .^{15}$

\footnotetext{
${ }^{13} \mathrm{~A}$ two-sided Wilcoxon rank-sum test (using average revenue within the 12 matching groups and phases as inpedendent unit of observation) generates p-values of $0.002,0.002$, and 0.938 respectively for phases 1,2 , and 3 .

${ }^{14}$ The two-sided Wilcoxon rank-sum test generates p-values of $0.002,0.038$, and 0.002 respectively for phases 1,2 , and 3 .

${ }^{15}$ The two-sided Wilcoxon rank-sum test generates p-values of $0.000,0.003$, and 0.119 respectively for phases 1,2 , and 3 .
} 
Our third result is the striking difference between the obtained revenue in CSA and SPSB in the first two phases of the experiment, which disappears in the third phase. In the case of inexperienced bidders, revenue tends to be (much) higher when bidders are confronted with the exposure problem than if they are not. Learning seems practically absent in SPSB: overbidding is consistent within and between phases. Subjects do learn when playing CSA in the sense that over time, revenue decreases to the equilibrium level. It seems that subjects only realize after playing SPSB that they should bid more cautiously in CSA. Indeed, within subject comparisons reveal that there is no statistical difference between the revenue in SPSB in one phase and in CSA in the next. ${ }^{16}$ At the end of this section, we discuss to which extent bidding converges to the equilibrium strategies.

Result 3 shows that subjects learn. In the case of inexperienced bidders, revenue tends to be (much) higher when bidders are confronted with the exposure problem than if they are not. However, this difference disappears in the last phase of our experiment. The reasons behind learning are two-fold. First, subjects learn from experience, i.e., subjects learn from a game something relevant for the same game. Second, subjects are able to do "transfer learning" (i.e., subjects learn from a game something relevant for another; see, Cooper and Kagel 2003). An OLS regression illustrates that both learning modes are relevant in our experiment (see Table 1 for the results). The regression estimates the revenue on the treatment variable and considers various time effects. ${ }^{17}$

[Insert Table 1 about Here]

The dummies $\mathrm{CSA}_{\varphi}$ denote the treatment variables for phases $\varphi=1,2,3$. With

\footnotetext{
${ }^{16} p=0.272[p=0.530]$ from phase $1[2]$ to phase 2 [3] (two-sided Wilcoxon signed-rank test). The other way around: there is a statistically significant difference between the revenue in CSA in a phase and SPSB in the following: $p=0.002[p=0.028]$ from phase 1 [2] to phase 2 [3] (two-sided Wilcoxon signed-rank test).

${ }^{17}$ The regression includes dummies for each subject. Robust standard errors are calculated to account for statistical dependence within matching groups.
} 
respect to phase $\varphi, \mathrm{CSA}_{\varphi}=1$ for treatment $\mathrm{CSA}$, and $\mathrm{CSA}_{\varphi}=1$ for treatment $\mathrm{SPSB}$. The estimated coefficients confirm that CSA generates higher revenues in phases 1 and 2 . Again, revenue is not significantly higher for $\mathrm{CSA}$ in phase $3 . \mathrm{CSA}_{\varphi} \mathrm{xPERIOD}$ interacts the treatment effect with relevant period within a phase $\left(\operatorname{PERIOD}_{\varphi}=1,2, \ldots, 30\right.$ in phase $\varphi$ and $\operatorname{PERIOD}_{\varphi}=0$ otherwise). For phase 1 , the estimated negative coefficient of this variable indicates that revenue in CSA decreases faster from one period to the next than in SPSB. In contrast, the overall time trend is insignificant. This means that subjects in CSA learn from experience whereas subjects in SPSB do not. The estimated coefficients of all other period variables are statistically insignificant: apart from CSA in phase 1, there is no overall time trend. This means that we only observe experience learning in CSA in phase 1. Because subjects who started out in SPSB have no prior experience with CSA, this means that subjects engage in transfer learning.

\subsection{Results: efficiency}

Efficiency is defined as follows

$$
\text { Efficiency }=\frac{\text { value of the winning bidder }}{\max \left\{v_{1}, v_{2}\right\}} \text {. }
$$

Propositions 1 and 2 predict that both auctions are $100 \%$ efficient. In a worst case scenario, if the two chopsticks are assigned using a lottery, expected efficiency equals 75\%. ${ }^{18}$ Figure 2 includes the average efficiency across auctions and phases. In CSA, we

\footnotetext{
${ }^{18}$ The calculation for this number is the following. As both bidders are ex ante symmetric, we may assume without loss of generality, that the lottery always assigns two chopsticks to bidder 1. Expected efficiency is then given by

$$
\begin{aligned}
\text { Expected efficieny } & =\int_{0}^{100}\left[\int_{0}^{v_{2}} \frac{v_{1}}{v_{2}} * \frac{1}{100} d v_{1}+\int_{v_{2}}^{100} 1 * \frac{1}{100} d v_{1}\right] \frac{1}{100} d v_{2} \\
& =\frac{3}{4}
\end{aligned}
$$

The first term in the inner integral refers to the case that bidder 2 has a higher value than bidder 1 (so that efficiency equals $\frac{v_{1}}{v_{2}}$ ). In the second term, bidder 1 has the higher value (so that efficiency equals 1 ).
} 
observe an average efficiency equal to $89 \%$ in all phases. This number is roughly as close to the efficiency of a lottery (75\%) and an efficient outcome (100\%). For SPSB, efficiency was about $95 \%$ in each phase. The efficiency of SPSB is much closer to the theoretical prediction of $100 \%$ than the outcome of a lottery. We conclude that

\title{
Result $4 S P S B$ is more efficient than $C S A .^{19}$
}

\author{
[Insert Figure 2 about Here]
}

\subsection{Results: bidding behavior}

Let us take a closer look at bidding behavior to examine why the experimental outcomes in terms of revenue and efficiency deviate from the theory, even after subjects had ample opportunity to learn.

Table 2 gives a summary of bidding behavior in CSA in the third phase. We have constructed this table as follows. For every bidder, we have calculated the absolute difference between her actual bids and six bidding strategies: the Bayesian Nash equilibrium, "bidding half your value", "bidding value", "always bid zero", a step function with bids equal to zero [fifty] for values below [above] 50, and a step function with bids equal to zero [100 or more] for values below [above] 50. Table 3 shows which of these bidding strategies has the lowest average absolute difference with the actual bids. When the average difference was more than 20, we classified the bidding strategy as "other". It turns out that simple strategies like "bidding half your value", bidding zero, and step functions are far more employed than the Bayesian Nash equilibrium. Still, the Bayesian Nash equilibrium is the best predictor among the six bidding strategies if we aggregate all bids in the third

\footnotetext{
${ }^{19}$ The two-sided Wilcoxon rank-sum test generates p-values of $0.002,0.028$, and 0.009 for phases 1,2 , and 3 respectively. Also within subject comparisons reveal a statistically significant difference: $p=0.005$ $[p=0.008 ; p=0.002 ; p=0.029]$ for CSA in phase $1[2 ; 2 ; 3]$ and SPSB in phase $2[1 ; 3 ; 2]$ (Wilcoxon signed-rank test).
} 
phase. The average absolute difference between the equilibrium bids and the true bids is 29.4. Inefficiencies arise because bidders employ different strategies and some of these strategies are not strictly increasing in value.

[Insert Table 2 about Here]

Subjects may have good reasons to deviate from the risk-neutral Bayesian Nash equilibrium in CSA. First, the best response to an opponent bidding his value is to always bid 0, which could explain why this strategy is a good proxy of the strategies followed by $15 \%$ of the bidders. Second, the best response for bidder $i$ to bidder $j$ bidding $\frac{v_{j}}{2}$ is to bid 0 for $v_{i}<50$ and (more than) 100 otherwise, a strategy that was also followed by $15 \%$ of the subjects. Both observations suggest that a substantial number of bidders may have in mind that other bidders use these simple linear bidding strategies.

Bidding in SPSB appears to be much closer to the theoretical prediction. According to table 3 , in the third phase, the far majority of subjects follows a bidding strategy that is close to the equilibrium strategy of "bidding half your value". Still, there is quite some overbidding: about $33 \%$ of the bids exceeds the equilibrium bid by more than $10 \%$. This explains why revenue is higher and efficiency lower than predicted by the theory.

[Insert Table 3 about Here]

\section{Conclusions}

In this paper, we have investigated the effect of the exposure problem on bidding behavior in auctions. With respect to revenue we have shown that inexperienced bidders strongly suffer from the exposure problem in CSA. In phase 1 of our experiment, revenues from CSA are 58 percent higher than in SPSB. However, we have also found significant learning 
effects. If bidders who are experienced in one trading institution in phase 1 are confronted with the other one in phase 2 (e.g., those who traded in SPSB, now trade in CSA), the negative effects of the exposure problem are much weaker than before. Therefore, subjects seem to engage in "transfer learning" (Cooper and Kagel, 2003). Finally, when trading is repeated under constant conditions in phase 3, the exposure problem ceases to have significant effects on revenue. With respect to efficiency our results are less optimistic: CSA is less efficient than SPSB and this result is robust to learning.

These results do not necessarily mean that the government should always avoid the exposure problem. In the case that the government does not have the necessary information as to how to put together sufficiently large licenses, it may consider splitting up supply in small licenses and "leave it to the market" how bidders put together packages of licences. The bidders could sort out themselves how many units they need to secure sufficient surplus. Depending on the shape of demand, the government may then design an auction in which the exposure problem is present. Our experiment has shown that this need not have a detrimental effect on revenue, but that the outcome is more likely to be inefficient. 


\section{A Appendix}

This appendix contains the proof of proposition 1 and instructions for the experiment.

\section{A.1 Proof of Proposition 1}

Let $B$ be a symmetric equilibrium bid function. Suppose $B$ is strictly increasing. If the other bidder bids according to $B$, the expected utility of a bidder with signal $v$ who bids as if she has signal $w$ is given by

$$
U(v, w)=\int_{0}^{w}(v-2 B(x)) d F(x)-(1-F(w)) B(w) .
$$

The first [second] term of the RHS refers to the case that the bidder makes the [second] highest bid. The FOC of the equilibrium is

$$
\frac{\partial U(v, w)}{\partial w}=(v-2 B(w)) f(w)-(1-F(w)) B^{\prime}(w)+f(w) B(w)=0
$$

at $w=v$. If the FOC holds true, also the $\mathrm{SOC}$ is fulfilled because

$$
\operatorname{sign}\left(\frac{\partial U(v, w)}{\partial w}\right)=\operatorname{sign}\left(\frac{\partial U(v, w)}{\partial w}-\frac{\partial U(w, w)}{\partial w}\right)=\operatorname{sign}(v-w) \text {. }
$$

Rearranging terms in (2), we derive the following differential equation:

$$
\begin{aligned}
\frac{B^{\prime}(v)}{1-F(v)}+\frac{f(v)}{(1-F(v))^{2}} B(v) & =v \frac{f(v)}{(1-F(v))^{2}} \Leftrightarrow \\
\frac{B(v)}{1-F(v)} & =\int_{0}^{v} x \frac{f(x)}{(1-F(x))^{2}} d x+C \\
& =\frac{v}{1-F(v)}-\int_{0}^{v} \frac{1}{1-F(x)} d x+C .
\end{aligned}
$$

Is the readily verified that the integration constant $C=0$, so that (1) follows. Uniqueness follows from a standard argument (see e.g., Bulow et al. 1999). 


\title{
A.2 Instructions for the experiment
}

\author{
These are instructions for treatment SPSB-CSA-SPSB. The ones for the \\ CSA-SPSB-CSA-treatment are similar.
}

\section{General information}

You are taking part in an economics experiment. If you have questions, please raise your hand. We will gladly answer your questions individually. From now until the end of the session, unauthorized communication of any kind between participants is not allowed. It is very important that you follow this rule. Otherwise the results of the experiment will be of no value from a scientific perspective. Please do not use the computer for any other purpose than participating in this study. Also, please turn off your cell phones.

The purpose of the experiment is to analyze decision behavior in markets.

You will receive a show up fee of $\$ 10$. If you carefully read the instructions and follow the rules you can earn additional money during the experiment. In this experiment you earn ECU (Experimental Currency Units). ECU will be converted to dollars with at a rate of

$$
1 \mathrm{ECU}=1 \text { cent. }
$$

Your final payoff consists of the initial $\$ 10$ given to you at the beginning of the experiment and the money you earn in the course of the experiment. You will be paid immediately after the experiment in cash. The experiment consists of three phases. 


\section{Detailed instructions Phases I and III}

In this experiment each participant is a buyer. You and one other buyer will participate in an auction in order to obtain units of a good. There are two possible outcomes. Either you obtain one unit, or you obtain two units. If you obtain only one unit, this is of no value for you. If you obtain two units, they will have a positive value (valuation) for you.

To illustrate this situation, suppose you want to have Chinese food and need chopsticks to eat it. While one chopstick is of no use whatsoever, with two chopsticks you can have your meal. However, as people are not always equally hungry the valuation will not be always the same. Actually, that valuation is a randomly determined integer between 0 and 100 , that is, each number between 0 and 100 is equally likely to occur. Your valuation is private information, i.e. neither you know the other buyer's valuation nor does the other buyer know your valuation.

Each buyer is informed of his or her own valuation and then asked to submit a bid. The one who submitted the higher bid is called the winner and buys two units of the good. The buyer who submitted the lower bid gets one (worthless) unit for free. Only the winner pays the price for each of its two units. This price equals the lower of the two submitted bids. If the two bids are the same the winner is randomly determined; that is, each buyer is equally likely to be the winner. The price and your valuation determine what you earn or lose.

If you are the winner, i.e. you submitted the higher bid, you buy two units. These units have a positive value for you but you have to pay the price for each of them, i.e. you earn a number of ECU equal to your valuation minus two times the price (the other's bid that is lower than yours). If you submitted the lower bid you get one useless unit for free. This is of no value for you but you do not have to pay the price (your submitted bid) for this unit. Summarizing, if you are the winner you get two units, therefore: 
profit $=$ valuation $($ valuation is the value of two units for you $)-2^{*}$ price $($ price is the bid of the other participant)

If you are not the winner you get one unit, therefore:

profit $=\mathbf{0}$ (the value of one unit for you is 0$)-\mathbf{0}($ you get one unit for free $)=\mathbf{0}$

The experiment consists of $\mathbf{3}$ trial periods and $\mathbf{3 0}$ trading periods.

The 3 trial periods will not account for your final earnings. In these trial periods you are going to be informed of your valuation and asked to submit a bid. However, in the trial periods you are not going to be matched with another real buyer. Instead, the computer is going to randomly generate the other buyer's bid. In a second screen you are going to be informed of the other's bid. To check your understanding of the auction rules you will have to answer some questions in this screen. Once your answers are correct you will be able to proceed. In order to make your life easier you are allowed to use a calculator which will pop up by clicking the button in the lower right corner of your screen.

After 3 trial periods there will come $\mathbf{3 0}$ trading periods. You are going to start the trading periods with 300ECU in your account. In the trading periods you are going to be informed of your valuation and asked to submit a bid. On each of the trading periods you are going to be randomly matched with another buyer. This will be another participant in this room. You will never know whom you are matched with. In every period you and every other buyer are assigned new valuations for obtaining two units of the good. Note that your valuation is very likely to differ from other buyers' valuations. After everybody submits their bids you will see the results at the bottom of the screen. There you can 
check for every period your valuation, your bid, the other's bid, the price per unit, your profit, and your accumulated profits in this phase.

\section{Good Luck!}

\section{Detailed instructions Phase II}

In this experiment each participant is a buyer. You and one other buyer will participate in an auction in order to obtain units of a good. There are two possible outcomes. Either you obtain one unit, or you obtain two units. If you obtain only one unit, this is of no value for you. If you obtain two units, they will have a positive value (valuation) for you.

To illustrate this situation, suppose you want to have Chinese food and need chopsticks to eat it. While one chopstick is of no use whatsoever, with two chopsticks you can have your meal. However, as people are not always equally hungry the valuation will not be always the same. Actually, that valuation is a randomly determined integer between 0 and 100 , that is, each number between 0 and 100 is equally likely to occur. Your valuation is private information, i.e. neither you know the other buyer's valuation nor does the other buyer know your valuation.

Each buyer is informed of his or her own valuation and then asked to submit a bid. The one who submitted the higher bid is called the winner and buys two units of the good. The buyer who submitted the lower bid has to buy one unit. For every unit you buy, you have to pay its price. This price equals the lower of the two submitted bids. If the two bids are the same the winner is randomly determined; that is, each buyer is equally likely to be the winner. The price and your valuation determine what you earn or lose.

If you are the winner, i.e. you submitted the higher bid, you buy two units. These 
units have a positive value for you but you have to pay the price for each of them, i.e. you earn a number of ECU equal to your valuation minus two times the price (the other's bid that is lower than yours). If you submitted the lower bid you buy only one unit. This is of no value for you but you have to pay the price (your submitted bid) for this unit. Summarizing, if you are the winner you get two units, therefore:

profit $=$ valuation $($ valuation is the value of two units for you $)-\mathbf{2}^{*}$ price $($ price is the bid of the other participant)

If you are not the winner you get one unit, therefore:

profit $=\mathbf{0}$ (the value of one unit for you is 0 ) - price (if you are not the winner the price is your bid)

The experiment consists of 3 trial periods and 30 trading periods.

The 3 trial periods will not account for your final earnings. In these trial periods you are going to be informed of your valuation and asked to submit a bid. However, in the trial periods you are not going to be matched with another real buyer. Instead, the computer is going to randomly generate the other buyer's bid. In a second screen you are going to be informed of the other's bid. To check your understanding of the auction rules you will have to answer some questions in this screen. Once your answers are correct you will be able to proceed. In order to make your life easier you are allowed to use a calculator which will pop up by clicking the button in the lower right corner of your screen.

After 3 trial periods there will come 30 trading periods. You are going to start the 
trading periods with 300ECU in your account. In the trading periods you are going to be informed of your valuation and asked to submit a bid. On each of the trading periods you are going to be randomly matched with another buyer. This will be another participant in this room. You will never know whom you are matched with. In every period you and every other buyer are assigned new valuations for obtaining two units of the good. Note that your valuation is very likely to differ from other buyers' valuations. After everybody submits their bids you will see the results at the bottom of the screen. There you can check for every period your valuation, your bid, the other's bid, the price per unit, your profit, and your accumulated profits in this phase.

\section{Good Luck!}




\section{Acknowledgements}

We are grateful for financial support by the Austrian National Bank (Jubilaeumsfonds, Project No. 9134), the Dutch National Science Foundation (ESR 510.010.501 and NWOVICI 453.03.606) and Harvard Business School. Moreover, we would like to thank Dan Kovenock and 2 anonymous referees of IJIO, the organizers of BEAUTY2001, Steffen Huck, Kasper Leufkens, Theo Offerman, Jean Tirole, and participants at seminars at the university of Munich and Antwerp, the FEEM conference on auctions, the NAKE research day, and the EEA2004 and IIOC2006 meetings for useful comments.

\section{References}

Ausubel, L. M., Cramton, P., 1999. The optimality of being efficient. Working paper, University of Maryland.

Barut, Y., Kovenock, D.,Noussair, C., 2002. A comparison of multiple-unit all-pay and winner-pay auctions under incomplete information. International Economic Review $43,675-707$.

Baye, M.R., Kovenock, D., de Vries, C., 1998. A general linear model of contests. Working paper, Indiana University.

Binmore, K., Swierzbinski, J. 2000. Treasury auctions: uniform or discriminatory? Review of Economic Design 5, 387 - 410.

Börgers, T., Dustmann, C. 2005. Strange bids: Bidding behaviour in the United Kingdom's third generation spectrum auction. Economic Journal 115, 551 - 578.

Bulow, J., Huang, M., Klemperer, P., 1999. Toeholds and takeovers. Journal of Political Economy 107, 427 - 454.

Bykowsky, M., Cull, R., Ledyard, J., 2000. Mutually destructive bidding: the FCC auction design problem. Journal of Regulatory Economics 17, 205 - 228.

Cooper, D.J., Kagel, J.H., 2003. Lessons learned: Generalizing across games. American Economic Review 93, 202 - 207. 
Coppinger, V. M., Smith, V. L., Titus, J. A., 1980. Incentives and behavior in English, Dutch and sealed-bid auctions. Economic Inquiry 43, $1-22$.

Cox, J. C., Roberson, B., Smith, V. L., 1982. Theory and behavior of single object auctions. In: Smith, V.L. (Ed.), Research in Experimental Economics, Vol. 2. JAI Press, Greenwich.

Cramton, P. C., 1995. Money out of thin air: the nationwide narrowband PCS auction. Journal Economics and Management Strategy 2, 267 - 343.

Cramton, P. C., 1998. The efficiency of the FCC spectrum auctions. Journal of Law and Economics 41, $727-736$.

Davis, D. D., Holt, C. A., 1993. Experimental Economics. Princeton University Press, Princeton.

Davis, D., Reilly, R., 1998. Do too many cooks always spoil the stew? An experimental analysis of rent-seeking and the role of a strategic buyer. Public Choice 95, 89 - 115 .

Fischbacher, U., 1999. Z-Tree: Zurich toolbox for readymade economic experiments. Working paper 21, Institute for Empirical Research in Economics, University of Zurich.

Harstad, R. M., 2000. Dominant strategy adoption, efficiency, and bidders' experience with pricing rules, Experimental Economics 3, 261-280.

Kagel, J. H., 1995. Auctions: a survey of experimental research. In: Kagel, J.H., A. E. Roth (Eds.). Handbook of Experimental Economics. New Jersey: Princeton University Press, Princeton.

Kagel, J. H., Harstad, R. M., Levin, D., 1987. Information impact and allocation rules in auctions with affiliated private values: a laboratory study. Econometrica 55, 1275 1304.

Kagel, J. H., Levin, D., 1993. Independent private value auctions: bidder behavior in first-, second-, and third-price auctions with varying number of bidders. Economic Journal 103, $868-879$.

Klemperer, P., 2002. What really matters in auction design. Journal of Economic 
Perspectives 16, $169-189$.

Krishna, V., Rosenthal, R., 1996. Simultaneous auctions with synergies. Games and Economic Behavior 17, 1 - 31 .

McAfee, R., McMillan, J., 1996. Analyzing the airwaves auction. Journal of Economic Perspectives 10, $159-175$.

McMillan, J., 1994. Selling spectrum rights. Journal Economic Perspectives 8, 145 162.

Milgrom, P., 2000. Putting auction theory to work: the simultaneous ascending auction. Journal of Political Economy 108, 245 - 272.

Myerson, R., 1981. Optimal auction design. Mathematics of Operations Research 6, $58-73$.

Noussair, C., Silver, J., 2006. "Behavior in All-Pay Auctions with Incomplete Information," Games and Economic Behavior 55, 189 - 206.

Onderstal, S., 2002. The Chopstick Auction. CentER Discussion Paper 35, Tilburg University.

Potters, J., de Vries, C., Van Winden, F., 1998. An experimental examination of rational rent-seeking. European Journal of Political Economy 14, 783 - 800.

Rosenthal, R., Wang, R., 1996. Simultaneous auctions with synergies and common values. Games and Economic Behavior 17, 32 - 55 .

Szentes, B., Rosenthal, R., 2003a. Beyond chopsticks: symmetric equilibria in majority auction games. Games economic behavior 45, 278 - 295.

Szentes, B., Rosenthal, R., 2003b. Three-object two-bidder simultaneous auctions: chopsticks and tetrahedra. Games and Economic Behavior 44, 114 - 133.

Van Damme, E., 1999. The Dutch DCS-1800 auction. In: Patrone, F., I. GarciaJurado, S. Tijs (Eds.) Game Practice: Contributions From Applied Game Theory. Kluver Academic Publishers, Dordrecht.

Van Damme, E., 2002. The European UMTS-auctions. European Economic Review 
$46,846-869$. 
Tables and figures

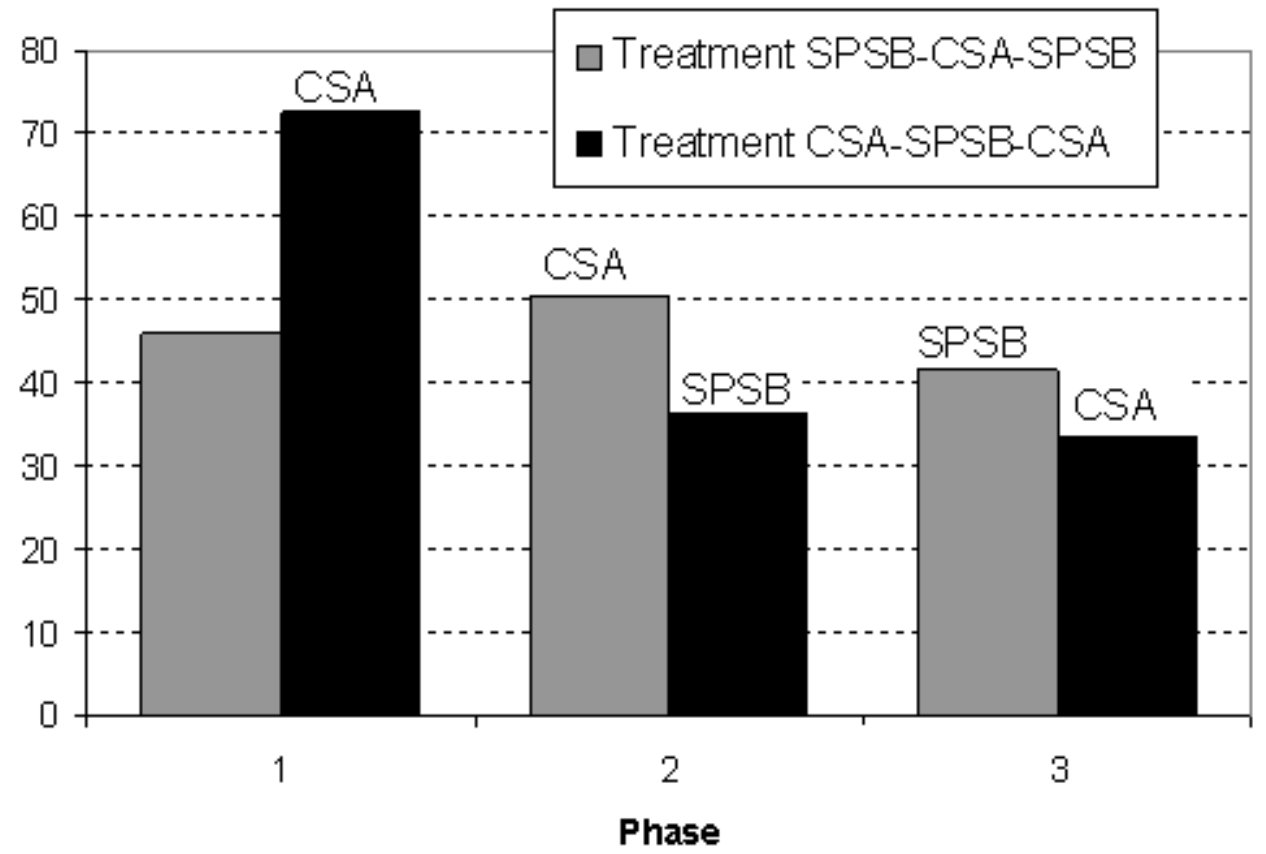

Figure 1: revenue in CSA and SPSB.

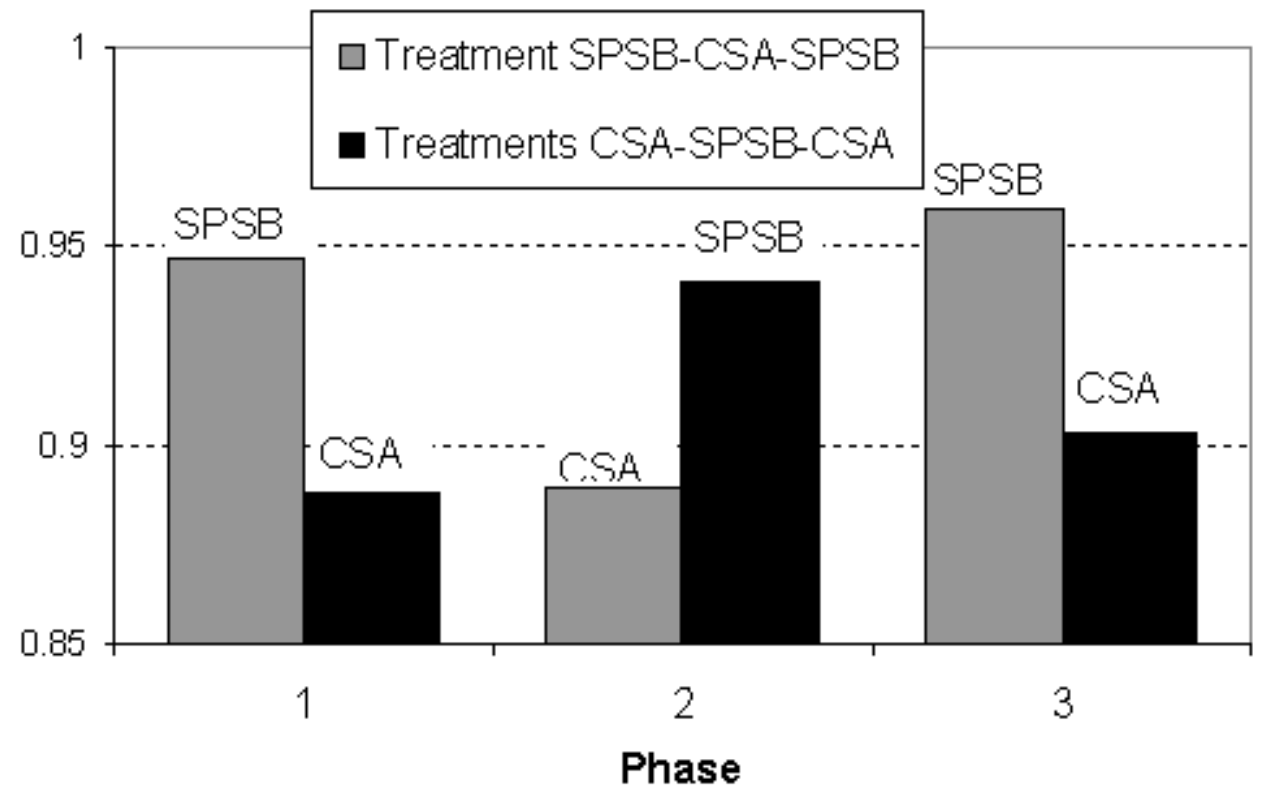

Figure 2: efficiency in CSA and SPSB. 


\begin{tabular}{|c|c|}
\hline Constant & $33.524(16.470)$ ** \\
\hline $\mathrm{CSA}_{1}$ & $50.137(5.619) * * *$ \\
\hline PERIOD $_{1}$ & $0.110(0.085)$ \\
\hline $\mathrm{CSA}_{1} \times \mathrm{PERIOD}_{1}$ & $-1.026(0.308)^{* * *}$ \\
\hline $\mathrm{CSA}_{2}$ & $9.887(3.927) * *$ \\
\hline PERIOD $_{2}$ & $-0.019(0.100)$ \\
\hline $\mathrm{CSA}_{2} \times \mathrm{PERIOD}_{2}$ & $-0.176(0.242)$ \\
\hline $\mathrm{CSA}_{3}$ & $-0.283(3.506)$ \\
\hline $\mathrm{PERIOD}_{3}$ & $-0.066(0.079)$ \\
\hline $\mathrm{CSA}_{3} \times \mathrm{PERIOD}_{3}$ & $-0.108(0.193)$ \\
\hline Observations & 8640 \\
\hline$R^{2}$ & 0.07 \\
\hline
\end{tabular}

Table 1: Estimates of the panel data regression. Robust standard errors in parentheses. *** $(* *)[*]$ indicates statistical significance at the $1 \%(5 \%)[10 \%]$ level.

\begin{tabular}{|l|l|l|l|l|l|l|l|}
\hline bid strategy & $B\left(v_{i t}\right)$ & $\frac{1}{2} v_{i t}$ & $v_{i t}$ & 0 & step $(0,50)$ & step $(0, \geq 100)$ & other \\
\hline & $8 \%$ & $31 \%$ & $8 \%$ & $15 \%$ & $8 \%$ & $15 \%$ & $15 \%$ \\
\hline
\end{tabular}

Table 2: The approximate bid strategies in CSA. $v_{i t}$ is the value of subject $i$ in period $t$ and $B\left(v_{i t}\right)$ is the theoretical prediction.

\begin{tabular}{|l|l|l|l|}
\hline$\leq 1$ & $\leq 2$ & $\leq 5$ & $\leq 10$ \\
\hline $46 \%$ & $52 \%$ & $65 \%$ & $77 \%$ \\
\hline
\end{tabular}

Table 3: Fraction of subjects in SPSB for whom the average absolute difference between the actual bids and the unique weakly dominant strategy does not exceed the given number. 


\section{CESifo Working Paper Series}

(for full list see www.cesifo-group.de)

1720 Ronald McKinnon and Gunther Schnabl, China's Exchange Rate and International Adjustment in Wages, Prices, and Interest Rates: Japan Déjà Vu?, May 2006

1721 Paolo M. Panteghini, The Capital Structure of Multinational Companies under Tax Competition, May 2006

1722 Johannes Becker, Clemens Fuest and Thomas Hemmelgarn, Corporate Tax Reform and Foreign Direct Investment in Germany - Evidence from Firm-Level Data, May 2006

1723 Christian Kleiber, Martin Sexauer and Klaus Waelde, Bequests, Taxation and the Distribution of Wealth in a General Equilibrium Model, May 2006

1724 Axel Dreher and Jan-Egbert Sturm, Do IMF and World Bank Influence Voting in the UN General Assembly?, May 2006

1725 Swapan K. Bhattacharya and Biswa N. Bhattacharyay, Prospects of Regional Cooperation in Trade, Investment and Finance in Asia: An Empirical Analysis on BIMSTEC Countries and Japan, May 2006

1726 Philippe Choné and Laurent Linnemer, Assessing Horizontal Mergers under Uncertain Efficiency Gains, May 2006

1727 Daniel Houser and Thomas Stratmann, Selling Favors in the Lab: Experiments on Campaign Finance Reform, May 2006

1728 E. Maarten Bosker, Steven Brakman, Harry Garretsen and Marc Schramm, A Century of Shocks: The Evolution of the German City Size Distribution 1925 - 1999, May 2006

1729 Clive Bell and Hans Gersbach, Growth and Enduring Epidemic Diseases, May 2006

1730 W. Bentley MacLeod, Reputations, Relationships and the Enforcement of Incomplete Contracts, May 2006

1731 Jan K. Brueckner and Ricardo Flores-Fillol, Airline Schedule Competition: ProductQuality Choice in a Duopoly Model, May 2006

1732 Kerstin Bernoth and Guntram B. Wolff, Fool the Markets? Creative Accounting, Fiscal Transparency and Sovereign Risk Premia, May 2006

1733 Emmanuelle Auriol and Pierre M. Picard, Government Outsourcing: Public Contracting with Private Monopoly, May 2006

1734 Guglielmo Maria Caporale and Luis A. Gil-Alana, Modelling Structural Breaks in the US, UK and Japanese Unemployment Rates, May 2006 
1735 Emily J. Blanchard, Reevaluating the Role of Trade Agreements: Does Investment Globalization Make the WTO Obsolete?, May 2006

1736 Per Engström and Bertil Holmlund, Tax Evasion and Self-Employment in a High-Tax Country: Evidence from Sweden, May 2006

1737 Erkki Koskela and Mikko Puhakka, Cycles and Indeterminacy in Overlapping Generations Economies with Stone-Geary Preferences, May 2006

1738 Saku Aura and Thomas Davidoff, Supply Constraints and Housing Prices, May 2006

1739 Balázs Égert and Ronald MacDonald, Monetary Transmission Mechanism in Transition Economies: Surveying the Surveyable, June 2006

1740 Ben J. Heijdra and Ward E. Romp, Ageing and Growth in the Small Open Economy, June 2006

1741 Robert Fenge and Volker Meier, Subsidies for Wages and Infrastructure: How to Restrain Undesired Immigration, June 2006

1742 Robert S. Chirinko and Debdulal Mallick, The Elasticity of Derived Demand, Factor Substitution and Product Demand: Corrections to Hicks' Formula and Marshall's Four Rules, June 2006

1743 Harry P. Bowen, Haris Munandar and Jean-Marie Viaene, Evidence and Implications of Zipf's Law for Integrated Economies, June 2006

1744 Markku Lanne and Helmut Luetkepohl, Identifying Monetary Policy Shocks via Changes in Volatility, June 2006

1745 Timo Trimborn, Karl-Josef Koch and Thomas M. Steger, Multi-Dimensional Transitional Dynamics: A Simple Numberical Procedure, June 2006

1746 Vivek H. Dehejia and Yiagadeesen Samy, Labor Standards and Economic Integration in the European Union: An Empirical Analysis, June 2006

1747 Carlo Altavilla and Paul De Grauwe, Forecasting and Combining Competing Models of Exchange Rate Determination, June 2006

1748 Olaf Posch and Klaus Waelde, Natural Volatility, Welfare and Taxation, June 2006

1749 Christian Holzner, Volker Meier and Martin Werding, Workfare, Monitoring, and Efficiency Wages, June 2006

1750 Steven Brakman, Harry Garretsen and Charles van Marrewijk, Agglomeration and Aid, June 2006

1751 Robert Fenge and Jakob von Weizsäcker, Mixing Bismarck and Child Pension Systems: An Optimum Taxation Approach, June 2006 
1752 Helge Berger and Michael Neugart, Labor Courts, Nomination Bias, and Unemployment in Germany, June 2006

1753 Chris van Klaveren, Bernard van Praag and Henriette Maassen van den Brink, A Collective Household Model of Time Allocation - a Comparison of Native Dutch and Immigrant Households in the Netherlands, June 2006

1754 Marko Koethenbuerger, Ex-Post Redistribution in a Federation: Implications for Corrective Policy, July 2006

1755 Axel Dreher, Jan-Egbert Sturm and Heinrich Ursprung, The Impact of Globalization on the Composition of Government Expenditures: Evidence from Panel Data, July 2006

1756 Richard Schmidtke, Private Provision of a Complementary Public Good, July 2006

1757 J. Atsu Amegashie, Intentions and Social Interactions, July 2006

1758 Alessandro Balestrino, Tax Avoidance, Endogenous Social Norms, and the Comparison Income Effect, July 2006

1759 Øystein Thøgersen, Intergenerational Risk Sharing by Means of Pay-as-you-go Programs - an Investigation of Alternative Mechanisms, July 2006

1760 Pascalis Raimondos-Møller and Alan D. Woodland, Steepest Ascent Tariff Reforms, July 2006

1761 Ronald MacDonald and Cezary Wojcik, Catching-up, Inflation Differentials and Credit Booms in a Heterogeneous Monetary Union: Some Implications for EMU and new EU Member States, July 2006

1762 Robert Dur, Status-Seeking in Criminal Subcultures and the Double Dividend of ZeroTolerance, July 2006

1763 Christa Hainz, Business Groups in Emerging Markets - Financial Control and Sequential Investment, July 2006

1764 Didier Laussel and Raymond Riezman, Fixed Transport Costs and International Trade, July 2006

1765 Rafael Lalive, How do Extended Benefits Affect Unemployment Duration? A Regression Discontinuity Approach, July 2006

1766 Eric Hillebrand, Gunther Schnabl and Yasemin Ulu, Japanese Foreign Exchange Intervention and the Yen/Dollar Exchange Rate: A Simultaneous Equations Approach Using Realized Volatility, July 2006

1767 Carsten Hefeker, EMU Enlargement, Policy Uncertainty and Economic Reforms, July 2006 
1768 Giovanni Facchini and Anna Maria Mayda, Individual Attitudes towards Immigrants: Welfare-State Determinants across Countries, July 2006

1769 Maarten Bosker and Harry Garretsen, Geography Rules Too! Economic Development and the Geography of Institutions, July 2006

1770 M. Hashem Pesaran and Allan Timmermann, Testing Dependence among Serially Correlated Multi-category Variables, July 2006

1771 Juergen von Hagen and Haiping Zhang, Financial Liberalization in a Small Open Economy, August 2006

1772 Alessandro Cigno, Is there a Social Security Tax Wedge?, August 2006

1773 Peter Egger, Simon Loretz, Michael Pfaffermayr and Hannes Winner, Corporate Taxation and Multinational Activity, August 2006

1774 Jeremy S.S. Edwards, Wolfgang Eggert and Alfons J. Weichenrieder, The Measurement of Firm Ownership and its Effect on Managerial Pay, August 2006

1775 Scott Alan Carson and Thomas N. Maloney, Living Standards in Black and White: Evidence from the Heights of Ohio Prison Inmates, 1829 - 1913, August 2006

1776 Richard Schmidtke, Two-Sided Markets with Pecuniary and Participation Externalities, August 2006

1777 Ben J. Heijdra and Jenny E. Ligthart, The Transitional Dynamics of Fiscal Policy in Small Open Economies, August 2006

1778 Jay Pil Choi, How Reasonable is the 'Reasonable' Royalty Rate? Damage Rules and Probabilistic Intellectual Property Rights, August 2006

1779 Ludger Woessmann, Efficiency and Equity of European Education and Training Policies, August 2006

1780 Gregory Ponthiere, Growth, Longevity and Public Policy, August 2006

1781 Laszlo Goerke, Corporate and Personal Income Tax Declarations, August 2006

1782 Florian Englmaier, Pablo Guillén, Loreto Llorente, Sander Onderstal and Rupert Sausgruber, The Chopstick Auction: A Study of the Exposure Problem in Multi-Unit Auctions, August 2006 